\title{
Influence of dietary linoleic acid on leucocyte sodium transport and blood pressure
}

\author{
A M HEAGERTY, J D OLLERENSHAW, D I ROBERTSON, R F BING, J D SWALES
}

\begin{abstract}
In a randomised double blind study to determine whether an increase in the polyunsaturated fat linoleic acid might influence leucocyte membrane sodium transport 22 normotensive volunteers received an oral supplement of linoleic acid or placebo daily for four weeks. Mean total sodium efflux rose significantly during supplementation with linoleic acid compared with placebo. In addition, all components of lying and standing blood pressure fell, though only the fall in supine systolic pressure was significant.

Dietary supplementation with linoleic acid may alter ion fluxes across the cell membrane, presumably through changes in its physicochemical structure. In addition, the change in fat intake may lower blood pressure, though to only a very modest extent.
\end{abstract}

\section{Introduction}

The cellular abnormality that generates essential hypertension has been the subject of recent intense investigation. A large number of disturbances of plasma membrane function have been reported in cells of hypertensive patients. ${ }^{1}$ These were initially confined to the handling of univalent cations such as sodium,,$^{23}$ but workers have now also identified disturbances in calcium binding and efflux. ${ }^{45}$ Some of these mechanisms have been found to be disordered in the normotensive offspring of hypertensive patients, ${ }^{6-8}$ and it has been suggested that they may be markers of a genetically determined alteration in the physicochemical structure of the plasma membrane. ${ }^{910}$ The site of this membrane abnormality may well lie in the lipid fraction; $;^{19}$ membrane microviscosity ${ }^{11}$ and sialic acid content ${ }^{12}$ are deranged in hypertension, and the linoleic acid content of membranes from patients with atherosclerosis is reduced. ${ }^{13}$ The make up of fatty acids determines the activity of many phospholipids, ${ }^{14}$ and these in turn influence the membrane handling of cations such as sodium. ${ }^{15}$ Much interest has been aroused by the finding that blood pressure may be lowered by changing to a vegetarian diet, ${ }^{16}$ which alters membrane fatty acid composition. ${ }^{17}$ The exact component in this diet that lowers blood pressure is unclear, but the increased polyunsaturated fatty intake has been suspected. ${ }^{18}$ We therefore decided to examine whether increasing just one dietary constituent such as linoleic acid might effect a change in the intrinsic characteristics of the plasma membrane and thereby influence membrane sodium transport, and perhaps also alter blood pressure.

\section{Subjects and methods}

Twenty two healthy normotensive volunteers were recruited from hospital staff, university students, and members of the public responding to

\footnotetext{
Department of Medicine, Clinical Sciences Building, Leicester Royal Infirmary, PO Box 65, Leicester LE2 7LX

A M HEAGERTY, MB, MRCP, lecturer in medicine

I D OLLERENSHAW, research technician

D I ROBERTSON, MA, MRCP, registrar in medicine

R F BING, MB, FRCP, senior lecturer in medicine

J D SWALES, MD, FRCP, professor of medicine

Correspondence to: Dr Heagerty.
}

a local advertisement. Nine were men, all were omnivorous, and none had a family history of hypertension. Table I gives the characteristics of the group.

The aim of the study was to determine whether the ingestion of linoleic acid and subsequent incorporation into the cell membrane would change univalent cation handling characteristics. Blood pressure was also monitored because it has been postulated that this is influenced by changes in transmembrane sodium movements. We selected a double blind, placebo controlled crossover design for the trial. Subjects were randomised to receive active or placebo treatment and crossed over to the second treatment so that any order effect could be assessed. Random numbers were obtained from scientific tables (Documenta Geigy, 1975). On recruitment volunteers were weighed and had their lying and standing blood pressures recorded. All subjects provided three successive 24 hour urine collections for estimation of sodium $\left(\mathrm{Na}^{+}\right)$and potassium $\left(\mathrm{K}^{+}\right)$excretion. Linoleic acid was administered as eight safflower seed oil capsules a day. Each capsule contained $500 \mathrm{mg}$ oil, of which $72 \%$ was linoleic acid. We calculated that this would increase the average daily linoleic acid intake by roughly $40 \%$. Placebo capsules were identical with active supplements and contained paraffin. Subjects continued taking capsules for 28 days, and at the end of that time they were reweighed, had their blood pressure measured again, and gave venous blood for membrane fatty acid estimation and leucocyte sodium transport studies.

TABLE I-Baseline characteristics of 22 subjects studied. (Mean values expressed with $S E M$ in parentheses)

\begin{tabular}{|c|c|c|c|c|c|c|c|}
\hline \multicolumn{2}{|c|}{ Sex } & \multirow{2}{*}{$\begin{array}{c}\text { Age } \\
\text { (years) }\end{array}$} & \multirow{2}{*}{$\begin{array}{c}\text { Weight } \\
(\mathrm{kg})\end{array}$} & \multicolumn{2}{|c|}{ Blood pressure $(\mathrm{mm} \mathrm{Hg})$} & \multicolumn{2}{|c|}{$\begin{array}{c}\text { Urinary } \\
\text { electrolytes } \\
(\mathrm{mmol} / 24 \mathrm{~h})\end{array}$} \\
\hline$M$ & $\mathrm{~F}$ & & & Lying & Standing & Sodium & Potassium \\
\hline 9 & 13 & $25(1 \cdot 3)$ & $66(3 \cdot 2)$ & $128(3 \cdot 5) / 68(2 \cdot 6)$ & $120(3 \cdot 5) / 80(2 \cdot 0)$ & $152(7 \cdot 5)$ & $66(3 \cdot 2)$ \\
\hline
\end{tabular}

A 24 hour urine collection was saved during the last day of the diet for estimation of urinary sodium and potassium excretion. Subjects then had a 28 day wash out period before being crossed over to the other capsules, and after 28 days the studies were repeated.

Leucocyte sodium efflux rate constants were measured by the method of Milner et al. ${ }^{19}$ Sixty millilitres of venous blood were taken into tubes containing lithium-heparin as anticoagulant and transferred to universal containers holding Plasmagel (Uniscience, Cambridge) at $37^{\circ} \mathrm{C}$. White blood cells were separated from erythrocytes and platelets by differential sedimentation. After washing in tissue culture medium 199 (Gibco, Scotland) the cell suspension was split into two aliquots. One was labelled with sodium-22 (Radiochemicals, Amersham) and the other incubated unlabelled for estimation of intracellular sodium content. The radioactively labelled cells were washed after 30 minutes and timed aliquots taken in the presence and absence of ouabain. Leucocyte sodium efflux rate constants were calculated by linear regression.

Intracellular sodium constant was measured by washing the unlabelled leucocytes with $99 \mathrm{mmol}$ magnesium chloride, washing the cell pellet, and leeching out the sodium into deionised water. Electrolyte estimations were by flame photometry. The product of intracellular sodium and efflux rate constant gives the efflux rate for sodium in unit time.$^{20}$ Initial studies showed that electrolyte measurements remained stable with a coefficient of variation of $10 \%$ for total efflux rate constant and $17 \%$ for absolute efflux.

Membrane fatty acid estimations were performed on erythrocytes using the method of Rose and Ocklander. ${ }^{21}$ Red blood cells were washed in saline and lysed. The fatty acids were extracted into isopronalol/chloroform and methylated using sodium methoxide. Fatty acid methyl esters were identified using a Perkin Elmer F17 gas-liquid chromatograph.

Urinary sodium and potassium concentrations were estimated using a Corning flame photometer. Blood pressure was measured with a Hawksley random zero sphygmomanometer. Three readings were taken in both lying and standing positions and the average recorded.

Statistical analysis was by non-parametric sign testing on the data 
obtained at the end of each dietary period, as these were the two periods of the study that were randomised. Results for blood pressure and sodium transport are presented as means and standard errors of the means (SEM).

\section{Results}

All subjects completed the study: some felt bloated while taking safflower seed oil capsules but otherwise suffered no ill effects. No subject noted any change in bowel habit during the placebo period.

Weight and urinary electrolyte excretion-There was no significant change in mean weight while taking placebo compared with safflower oil (67 (SEM 3.6) $v 67(3 \cdot 2) \mathrm{kg})$. Similarly, neither urinary sodium nor potassium excretion was altered $(139(10.4) v 134(12 \cdot 9) \mathrm{mmol}(\mathrm{mEq})$ sodium/24 h; $71(4.5) v 71$ $(5 \cdot 0) \mathrm{mmol}(\mathrm{mEq})$ potassium $/ 24 \mathrm{~h})$.

Fatty acid composition-The coefficients of variations for the erythrocyte fatty acid estimations calculated from results from 10 subjects were as follows: palmitic acid (16:0) $4 \cdot 5 \%$, stearic acid (18:0) $4 \cdot 9 \%$, oleic acid $(18: 1 n-9) 5 \cdot 1 \%$, linoleic acid $(18: 2 n-6) 7 \cdot 7 \%$, arachidonic acid $(20: 4 n-6)$ $9 \cdot 4 \%$. In preliminary studies linoleic acid values were measured before and 28 days after the ingestion of the safflower seed oil capsules to make sure that the wash out period was long enough. There was no significant difference between the linoleic acid content at baseline and after the wash out period $(11 \cdot 73($ SEM 0.3$) v 11 \cdot 8(0.3) \% ; \mathrm{p}=0.76)$. During the study there was no significant change in the saturated fatty acids palmitic and stearic acid while taking safflower oil compared with placebo (table II). Similarly, values of oleic acid and arachidonic acid were unaltered. The content of linoleic acid, however, rose significantly with active treatment $(\mathrm{p}<0.01)$ (table II).

TABLE II-Mean (SEM) percentage erythrocyte membrane fatty acid content during treatment with placebo and safflower oil

\begin{tabular}{lll}
\hline & Placebo & Safflower oil \\
\hline $16: 0$ (Palmitic acid) & $25 \cdot 1(0 \cdot 37)$ & $24 \cdot 9(0 \cdot 32)$ \\
$18: 0$ (Stearic acid) & $23 \cdot 1(0 \cdot 18)$ & $23 \cdot 1(0 \cdot 19)$ \\
18: $\ln -9$ (Oleic acid) & $20 \cdot 3(0 \cdot 22)$ & $20 \cdot 1(0 \cdot 25)$ \\
$18: 2 \mathrm{n}-6$ (Linoleic acid) & $16 \cdot 3(0 \cdot 34)$ & $17 \cdot 0(0 \cdot 28)^{\star}$ \\
$20: 4 \mathrm{n}-6$ (Arachidonic acid) & $14 \cdot 8(0 \cdot 26)$ & $15 \cdot 1(0 \cdot 21)$ \\
\hline
\end{tabular}

${ }^{\star} \mathrm{p}<0 \cdot 01$.

Leucocyte sodium transport-During treatment with safflower oil the total leucocyte sodium efflux rate constant showed a small increase owing to a rise in the ouabain sensitive component, but this did not reach statistical significance (table III). Mean intracellular sodium content also increased with safflower oil, but this was not significant. The ouabain sensitive sodium efflux rate, however, showed a significant rise with safflower oil compared with placebo $(\mathrm{p}=0.039)$ (table III).

Blood pressure-Both systolic and diastolic pressures fell in the supine and standing positions with safflower oil compared with placebo (table IV). The

TABLE III-Mean (SEM) leucocyte sodium efflux rate constant, intracellular sodium, and efflux rate during treatment with placebo and safflower oil

\begin{tabular}{|c|c|c|c|c|c|c|c|}
\hline & \multicolumn{3}{|c|}{ Mean efflux rate constant $(h)$} & \multirow{2}{*}{$\begin{array}{c}\text { Intracellular } \\
\text { sodium } \\
\text { ( } \mathrm{mmol} / \mathrm{kg} \\
\text { dry weight } \\
\text { of cells) }\end{array}$} & \multicolumn{3}{|c|}{$\begin{array}{l}\text { Efflux rate }(\mathrm{mmol} / \mathrm{kg} \\
\text { dry weight of cells } / \mathrm{h})\end{array}$} \\
\hline & Total & $\begin{array}{l}\text { Ouabain } \\
\text { insensitive }\end{array}$ & $\begin{array}{l}\text { Ouabain } \\
\text { sensitive }\end{array}$ & & Total & $\begin{array}{l}\text { Ouabain } \\
\text { insensitive }\end{array}$ & $\begin{array}{l}\text { Ouabain } \\
\text { sensitive }\end{array}$ \\
\hline \multirow{2}{*}{$\begin{array}{l}\text { Placebo } \\
\text { Safflower } \\
\text { oil }\end{array}$} & $2 \cdot 2(0 \cdot 1)$ & $0 \cdot 8(0 \cdot 1)$ & $1 \cdot 4(0 \cdot 1)$ & $54(3 \cdot 0)$ & $114(8 \cdot 1)$ & $41(6 \cdot 2)$ & $72(5 \cdot 1)$ \\
\hline & $2 \cdot 3(0 \cdot 1)$ & $0.6(0.1)$ & $1 \cdot 7(0 \cdot 2)$ & $59(4 \cdot 4)$ & $134(11 \cdot 1)$ & $34(5 \cdot 1)$ & $100(9 \cdot 3)^{\star}$ \\
\hline
\end{tabular}

TABLE IV-Mean (SEM) lying and standing blood pressures ( $\mathrm{mm} \mathrm{Hg}$ ) during treatment with placebo and safflower oil

\begin{tabular}{cccccc}
\hline \multicolumn{2}{c}{ Placebo } & & \multicolumn{2}{c}{ Safflower oil } \\
\cline { 1 - 2 } \cline { 5 - 5 } Lying & Standing & & Lying & Standing \\
\hline $129(3 \cdot 3) / 68(1 \cdot 9)$ & $117(3 \cdot 4) / 75(2 \cdot 1)$ & & $125(3 \cdot 0)^{\star} / 66(1 \cdot 8)$ & $116(3 \cdot 3) / 73(1 \cdot 7)$ \\
\hline
\end{tabular}

${ }^{\star} \mathrm{p}<0.01$. fall in supine systolic pressure was highly significant $(p<0.01)$. There was no correlation between change in membrane linoleic acid and fall in pressure $(\mathbf{p}>0 \cdot 1)$.

Order effects - Data on all variables were analysed for possible treatment order effects after the study was concluded. Comparison of the first and $\mathbb{Q}$ second treatment and placebo period showed no difference, indicating that $c$ there was no order effect.

\section{Discussion}

This study shows that when the usual omnivorous diet of healthy volunteers was supplemented with linoleic acid the cellular membrane handling of sodium could be changed. In addition, a small fall $\stackrel{\oplus}{+}$ in blood pressure occurred, and both variables were influenced $\bar{C}$ while salt intake and body weight remained constant. Presumably $\frac{\bar{\sigma}}{\bar{\Omega}}$ the mechanism by which the change in sodium flux was brought $\frac{\bar{D}}{7}$

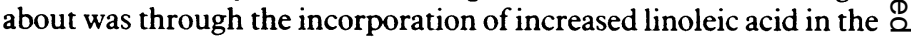
plasma membrane. The index of an incorporation of fat into the plasma membrane was a rise in erythrocyte membrane linoleic acid; $\overrightarrow{0}$ this tissue was used because the cells are relatively free of organelles whose membrane lipid composition might differ from that of the $\vec{\omega}$ plasma membrane itself. It is unlikely that the long plasma half life of these cells complicated these studies, as the fat composition of cell $\frac{0}{3}$ membranes varies with dietary intake. 22 The wash out period was also shown to be enough for the membranes to adjust from the dietary change.

Though the amount of linoleic acid incorporated was small, it was sufficient to achieve the objective of the experiment-namely, to alter the physicochemical structure and function of the cell mem- of brane assessed by its ability to extrude sodium. The efflux of sodium $ᄋ$ was enhanced by the sodium pump. This has several implications: $\stackrel{\sim}{N}$ firstly, it is clear that the influx of sodium into the cell was increased as a result of the dietary change. It is most likely that this was the prime effect of lipid incorporation, as the sodium pump is $\frac{}{\infty}$ stimulated by increases in intracellular sodium. We have no $\overrightarrow{\vec{t}}$ information on sodium influx, which will be examined in subsequent studies.

The second implication results from the small falls in blood $\bigcirc$ pressure in this study. Only the fall in supine systolic pressure reached statistical significance. Effects on other components of $\bar{\partial}$ blood pressure cannot be excluded, since the power of the study was such that there was an $80 \%$ chance of detecting a fall of $6 \mathrm{~mm} \mathrm{Hg} \stackrel{\mathbb{Q}}{\Omega}$ mean lying and $9 \mathrm{~mm} \mathrm{Hg}$ standing diastolic pressure. Evidence has $\overrightarrow{\overrightarrow{\vec{b}}}$ accumulated in recent years that an increase in the ratio of $\frac{0}{3}$ polyunsaturated to saturated fats in an omnivorous diet may lower blood pressure. ${ }^{18}$ Nevertheless, this finding is still controversial; $\frac{7}{0}$ Margetts and coworkers were unable to influence blood pressure in a group of volunteers by increasing the polyunsaturated to saturated fat ratio without altering overall fat intake. ${ }^{23}$ The nature of the dietary influence on blood pressure is thus uncertain. We changed $\frac{0}{3}$ one variable and lowered blood pressure by a comparable extent to that produced by adopting a vegetarian diet. ${ }^{24}$ Nevertheless, while the linoleic acid changed the membrane characteristics for sodium handling, the blood pressure lowering effects may well have been $\stackrel{5}{\supset}$ brought about by other influences of the lipid on membrane $\mathscr{N}$ function, since no net change in sodium distribution occurred. D In this regard it is interesting that supplementation of a normal Western diet with cod liver oil, which is rich in long chain $\omega 3 \overline{\mathrm{N}}$ polyunsaturated fatty acids, also lowered blood pressure but did N not change erythrocyte sodium cotransport or countertransport $\frac{\omega}{\sigma}$ characteristics. ${ }^{25}$ The properties of complex phospholipids are dependent on the fatty acid make up of the membrane, ${ }^{26}$ and both dietary supplements may well have altered their metabolism. Recent evidence suggests that these play an important part in the regulation of intracellular calcium ${ }^{27}$ and so may be important in the regulation of vascular contractility.

Clearly, in this study a small change in dietary fat caused a $\frac{O}{\mathbb{D}}$ fall in blood pressure. Further studies must now investigate, $\underset{\sigma}{\sigma}$ firstly, whether increasing the supplement might lower blood pressure further, and whether this simple regimen might be useful of in patients with essential hypertension. Furthermore, the influence of diet induced change on cell membrane composition and ion 
fluxes may provide important insight into the mechanism of hypertension.

We thank the British Heart Foundation for supporting this project.

\section{References}

1 Swales JD. Ion transport in hypertension. Biosci Rep 1982;2:967-90.

2 Edmondson RPS, Thomas RD, Hilton PJ, Patrick J, Jones NF. Abnormal leucocyte composition and sodium transport in essential hypertension. Lancet 1975; ; 1003-5.

3 Heagerty AM, Bing RF, Thurston H, Swales JD. Calcium antagonists in hypertension: relation to heagerty AM, Bing RF, Thurston H, Swales JD. Calcium a
abnormal sodium transport. Br.Med F 1983;287:1405-7.

4 Postnov YV, Orlov SN, Pokudin NI. Decrease of calcium binding by the red blood cell membrane

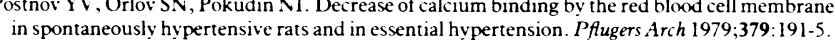
in spontaneously hypertensive rats and in essential hypertension. Pflugers Arch 1979;379:191-5.
Wei JW' Janis RA. Daniel EE. Calcium accumulation and enzymatic activities of subcellular ei JW, Janis RA, Daniel EE. Calcium accumulation and enzymatic activities of subcellular
fractions from aortas and ventricles of genetically hypertensive rats. Circ Res 1976;39:133-40. fractions from aortas and ventricles of genetically hypertensive rats. Circ Res 1976;39:133-40.
Heagerty AM, Milner M, Bing RF, Thurston H, Swales JD. Leucocyte membrane sodium transport in normotensive populations: dissociation of abnormalities of sodium efflux from raised blood pressure. Lancet 1982;ii:894-6.

7 Woods JW, Falk RJ, Pittman AW', Klemmer PJ, Watson BS, Namboodiri K. Increased red cell sodium-lithium countertransport in normotensive sons of hypertensive parents. N Engl f Med 1982;306:593-5

8 Mever P, Garay RP, Nazaret C, et al. Inheritance of abnormal erythrocyte cation transport in essential hypertension. Br.Med 7 1981;282:1114-7.

9 Heagerty AM, Riozzi A, Brand SC. Bing RF. Thurston H. Swales JD. Membrane transport of ions in hypertension: a review. Acta Med Scand 1985;46 suppl 180:54-64.

10 Postnov YV, Orlov SN. Cell membrane alteration as a source of primary hypertension. fournal of Hypertension 1984:2:1-6.

11 Montenav-Garestier T, Aragon I, Devynck K, Meyer P, Helene C. Evidence for structural changes in erythrocyte membranes of spontaneously hypertensive rats. A fluorescence changes in erythrocyte membranes of spontaneously hyperten

12 Reznikova MB, Adler AM, Postnov YV. Erythrocyte membrane sialic acids in primary and secondary hypertension in man and rat. Eur $\mathcal{F}$ Clin Incest 1984;14:87-9.
13 Wood DA. Butler S. Riemersma RA, et al. Adipose tissue and platelet fatty acids and coronary heart disease in Scottish men. Lancet 1984;ii: 117-22.

14 Kishimoto A, Takai Y, Mori T, Kikkawa U, Nishizuka Y. Activation of calcium and phospholipid-dependent protein kinase by diacylglycerol; its possible relation to
phention phospholipid-dependent protein kinase by diacylglycerol; its possible relation to
phosphatidylinositol turnover. $f$ Biol Chem 1980;255:2273-6.

15 Jorgensen PL. Isolation and characterization of the components of the sodium pump. $Q R e c$ Biophys 1975;7:239-74

16 Rouse JL, Beilin LJ. Vegetarian diet and blood pressure. Fournal of Hypertension 1984:2:231-40.

17 Sanders TAB, Ellis FR, Dickerson JW'T. Studies of vegans: the fatty acid composition of plasma choline phosphoglycerides, erythrocytes, adipose tissue and breast milk, and some indicators of susceptibility to ischemic heart disease in vegans and omnivore controls. Am J Clin Nutr 1978;31:805-13.

18 Puska P, Iacono JM, Nissinen A, et al. Controlled, randomized trial of the effect of dietary fat on blood pressure. Lancet 1983:i:1-5.

19 Milner M, Heagerty AM, Bing RF, Thurston H, Swales JD. Changes in leucocyte sodium transport in normotensive relatives of hypertensive subjects: dissociation from blood pressure. transport in normotensive re

20 Hilton PJ, Patrick J. Sodium and potassium flux rates in normal human leucocytes in an artificial extracellular fluid. Clin Sci 1973:44:439-45.

21 Rose $\mathrm{HG}$, Ocklander $\mathrm{M}$. Improved method for the extraction of lipids from human erythrocites. 7 Lipid Res 1965;6:428-31.

22 Kernoff BA, Willis AL, Stone KJ, Davies JA, McNicol GP. Antithrombotic porential of dihommo-gamma-linoleic acid. Br.Med $\mathcal{J}$ 1977; ii:1441-4

23 Margetts BM, Beilin JL, Armstrong BK, et al. Blood pressure and dietary polyunsaturated and saturated fats: a controlled trial. Clin Sci 1985; 69:165-75

24 Rouse IL, Beilin LJ, Armstrong BK, Vandongen R. Blood pressure lowering effect of a vegetarian diet: controlled trial in normotensive subjects. Lancet 1983;i:5-10.

25 Lorenz R, Spengler U, Fischer S, Duhm J, Weber PC. Platelet function, thromboxane formation and blood pressure control during supplementation of the Western diet with cod liver oil. Circulation 1983:67:504-11.

26 Roelofsen B. The non specificity in the lipid-requirement of calcium-and sodium plus potassium - transporting adenosine triphosphatases. Life $S_{c i}$ 1981;29:2335-47.

27 Tokumura A, Mostafa $\mathrm{MH}$, Nelson DR, Hanahan DJ. Stimulation of $\mathrm{Ca}^{2} \cdot \mathrm{Mg}^{2} \cdot$-ATPase activity in human erythrocyte membranes by synthetic lysophosphatidic acids and lysophatidylcholines. Effects of chain length and degree of unsaturation of the fattv acid groups. Biochem Biophys Acta 1985;812:568-74.

Accepted 23 May 1986

\title{
Increased incidence of menstrual abnormalities and hysterectomy preceding primary biliary cirrhosis
}

\author{
A J STELLON, ROGER WILLIAMS
}

\begin{abstract}
A study was performed to assess the incidence of previous hysterectomy and dilatation and curettage among women with primary biliary cirrhosis. In 87 patients with primary biliary cirrhosis hysterectomy or dilatation and curettage had been performed significantly more often than among 100 age matched normal controls and 80 age matched patients with chronic active hepatitis or alcoholic liver disease. Among the 47 patients with primary biliary cirrhosis who had undergone hysterectomy or dilatation and curettage operations had been performed at a mean of 10.7 years and 13.2 years, respectively, before the onset of disease. The main indication for hysterectomy among patients with primary biliary cirrhosis and controls was menorrhagia.

These menstrual disorders may be a consequence of high concentrations of oestrogens in patients with primary biliary cirrhosis.
\end{abstract}

\section{Introduction}

Both menorrhagia and amenorrhoea have been reported in association with chronic liver disease but not in women with primary biliary cirrhosis. In a study of patients with primary biliary cirrhosis we found an unexpectedly high proportion with menorrhagia, which had resulted in hysterectomy before the apparent onset of liver disease.

\section{Patients and methods}

Eighty seven consecutive patients with primary biliary cirrhosis, confirmed at biopsy, who were attending the outpatient department or being admitted for assessment were interviewed from January to December 1984. Patients' ages were in the range 35-70 years. A gynaecological and obstetric history was obtained from each patient, and when the patient had undergone anv gynaecological procedure the appropriate hospital was contacted and the operative and pathological findings obtained. The control groups, who were similarly interviewed, consisted of 100 age matched, healthy hospital staff and 80 age matched women with either chronic active hepatitis ( 45 patients) or alcoholic liver disease (35).

\section{Results}

The table shows that there was a striking difference between the patients with primary biliary cirrhosis and the control groups with respect to the proportion who had undergone hysterectomy. Furthermore, among patients with primary biliary cirrhosis hysterectomy had been performed a mean of $10 \cdot 7$ years (range 1-30 years) before the diagnosis of liver disease in 